\title{
Atributos químicos do solo afetado pelo manejo da água e do fertilizante potássico na cultura de arroz irrigado
}

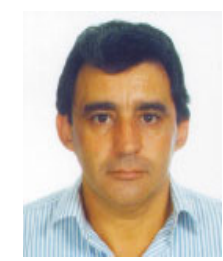

\author{
Alberto B. dos Santos ${ }^{1}$, Nand K. Fageria² \& Francisco J. P. Zimmermann ${ }^{2}$ \\ ${ }^{1}$ Embrapa Arroz e Feijão, CP 179, CEP 75375-000, Santo Antônio de Goiás, GO. Fone: (62) 533-2153, Fax: (62) 533-2100. \\ E-mail: baeta@cnpaf.embrapa.br (Foto) \\ ${ }^{2}$ Embrapa Arroz e Feijão. Fone: (62) 533-2178. E-mail: fageria@cnpaf.embrapa.br
}

Protocolo $030-20 / 3 / 2001$

\begin{abstract}
Resumo: O desenvolvimento das culturas nas várzeas é extremamente influenciado pelo manejo destas, devido aos atributos químicos e físico-hídricos que elas possuem. O decréscimo na produtividade, verificado no monocultivo contínuo de arroz (Oryza sativa L.) irrigado, pode estar relacionado à redução na fertilidade do solo, em decorrência da lixiviação de nutrientes. Com o objetivo de se avaliar os efeitos de manejo da água ( $\mathrm{MA}_{1}$ - inundação contínua e $\mathrm{MA}_{2}$ - inundação intermitente seguida de contínua) e do fertilizante potássico ( $\mathrm{K}_{1}$ - na semeadura; $\mathrm{K}_{2}$ - adubação parcelada $\mathrm{e}_{3}$ - meia dosagem parcelada) na cultura de arroz irrigado sobre alguns atributos químicos de um solo Gley Pouco Húmico, foram conduzidos experimentos durante três anos consecutivos. $\mathrm{Na}$ inundação contínua ocorre maior lixiviação de cálcio e de potássio, teor de fósforo no solo e saturação por alumínio e menor pH na camada superficial do solo em relação à inundação intermitente, além de aumento do teor de potássio e do pH e diminuição de saturação por alumínio em profundidade. A inundação intermitente e o parcelamento do potássio podem contribuir na redução das perdas de nutrientes em solos de várzea que apresentam percolação excessiva. Alguns atributos químicos do solo podem ser melhorados através do manejo adequado da cultura do arroz irrigado, envolvendo manejo da água e do fertilizante potássico.
\end{abstract}

Palavras-chave: nutrientes, pH, saturação por alumínio, soma de bases, lixiviação

\section{Chemical properties of soil affected by water and potassium fertilization management in irrigated rice}

\begin{abstract}
Crop performance in lowland soils is influenced by management practices due to change in physico-chemical properties. Grain yield decrease in continuous monoculture of irrigated rice (Oryza sativa L.) may be associated with decrease in soil fertility due to leaching of nutrients. The objective of this study was to evaluate effect of water management $\left(\mathrm{WM}_{1}\right.$ - continuous flooding, and $W_{2}$ - intermittent flooding followed by continuous flooding) and potassium fertilization ( $\mathrm{K}_{1}$ - at sowing; $\mathrm{K}_{2}$ - fractional application, and $\mathrm{K}_{3}$ - fractional application at half rate) on soil chemical properties of Low Humic Gley (Inceptisol) soil planted with irrigated rice during three consecutive years. Under continuous flooding treatment, there was more leaching of calcium and potassium, content of $\mathrm{P}, \mathrm{Al}$ saturation and low $\mathrm{pH}$ in the top $0-20 \mathrm{~cm}$ soil depth in relation to intermittent flooding. At lower soil depth, there was an increase in extractable $\mathrm{K}$ and $\mathrm{pH}$ and decrease in Al saturation. Intermittent flooding and fractional application of $\mathrm{K}$ can contribute in reducing nutrient leaching in lowland soils due to excessive water percolation. Some soil properties can be improved by crop management practices such as water and $\mathrm{K}$ management.
\end{abstract}

Key words: nutrients, $\mathrm{pH}$, aluminum saturation, sum of bases, leaching

\section{INTRODUÇÃO}

Tem-se verificado nas várzeas, especialmente nas mais arenosas, decréscimo na produtividade no monocultivo contínuo de arroz irrigado (Fageria et al., 1990; IRRI, 1994). Isto se deve à redução da fertilidade do solo, em decorrência da lixiviação de nutrientes, causada pela percolação excessiva da água. A lixiviação determina perda de nutrientes da zona radicular para camadas mais profundas do perfil do solo, tornando-os indisponíveis às culturas; portanto, é uma preocupação constante a lixiviação de íons provenientes da solução do solo ou de fertilizantes nas várzeas.

$\mathrm{O}$ volume de água percolado tem sido relatado como o principal responsável pelas perdas de nutrientes. A lixiviação de nutrientes varia com os atributos físicos do solo, como textura, estrutura, profundidade do perfil e, principalmente, porosidade. Entre os atributos químicos que afetam a lixiviação, estão a capacidade de troca de cátions (CTC) e o pH. Solos 
com alta CTC apresentam maior capacidade de adsorção dos cátions, tornando-os menos suscetíveis à lixiviação. Com o aumento do $\mathrm{pH}$, a CTC do solo se eleva e, conseqüentemente, os cátions disporão de maior número de cargas para adsorção.

Em função do fluxo de percolação profunda, Beltrame et al. (1991) verificaram linearidade crescente nas perdas por lixiviação de cátions em um Planossolo, com especial destaque para as perdas de cálcio. A escassez dos recursos naturais não renováveis é uma preocupação constante e, segundo Beltrame et al. (1992) os elementos e compostos químicos indispensáveis à produção agrícola adquirem fundamental importância. A submersão do solo causa aumento da condutividade elétrica da solução, ao promover a liberação de nitrogênio, fósforo, potássio, cálcio e magnésio para a solução do solo (Moraes \& Freire, 1974). Islam \& Islam (1973) observaram aumento da concentração de potássio na solução do solo e maior crescimento, produção e teor de nutrientes, em plantas de arroz cultivadas em solo submerso, que em plantas crescidas em solo com umidade na capacidade de campo. No solo submerso, as produções de $\mathrm{H}_{2} \mathrm{~S}$ e de ácidos orgânicos interferem, ao atingirem determinadas concentrações, nos processos de absorção de água e de nutrientes (Moraes, 1973); entretanto, devido ao sistema de irrigação contínua, acredita-se que esses compostos não se acumulem no solo em quantidades que possam afetar negativamente a produção agrícola, mas esse sistema de irrigação pode agravar a perda dos nutrientes do solo que são solubilizados, quando são modificadas as condições de oxirredução (Moraes \& Freire, 1974).

A inundação determina uma série de modificações físicoquímicas no solo, devido à ausência de $\mathrm{O}_{2}$ e à formação de uma camada onde ocorrem reações de redução e se desenvolvem organismos anaeróbicos. Estas modificações interferem na concentração dos nutrientes na solução do solo e, conseqüentemente, na sua possibilidade de lixiviação. Islam \& Ullah (1973) relataram que os benefícios da submersão podem ser equiparados à aplicação adicional de nutrientes na forma de fertilizantes no solo mantido na capacidade de campo. Os autores verificaram, também, em solo submerso, aumento da produtividade de arroz e da absorção de nutrientes. Stone et al. (1990) verificaram que a inundação contínua favoreceu a absorção de $\mathrm{P}$ e de Fe pelas plantas de arroz e apresentou menor eficiência de uso da água e, ainda, que a subirrigação, método de irrigação no qual a água é aplicada diretamente sob a superfície do solo, através da formação, manutenção e controle do lençol freático a uma profundidade preestabelecida, favoreceu a absorção de Mn.

Com a introdução de cultivares com maior potencial produtivo, tem-se verificado aumento na resposta do arroz irrigado ao fertilizante potássico. Fageria et al. (1990) obtiveram aumento significativo na produtividade de arroz irrigado, graças à aplicação de K. Em solos dos grupos Oxissolo e Hidromórfico, as maiores produtividades foram obtidas por Fageria (1991) com o parcelamento de $\mathrm{K}$ em arroz de terras altas e irrigado. As respostas ao $\mathrm{K}$ ocorrem principalmente em cultivos intensivos de arroz. Avaliando as perdas de alguns elementos químicos por lixiviação em um Planossolo Vacacaí de textura média, Beltrame et al. (1992) concluíram haver necessidade de parcelamento da aplicação de potássio, para aumentar a sua eficiência de utilização. Dentre os nutrientes que podem ser perdidos nos solos arenosos, Moraes \& Dynia (1992) consideraram o K como o cátion mais facilmente lixiviado, devido ao seu deslocamento para a solução do solo e à sua percolação.

Há necessidade de desenvolver sistemas adequados de produção, considerando-se as peculiaridades das várzeas, que apresentam atributos químicos e físico-hídricos próprios, já que é fundamental a manutenção, em níveis elevados, da fertilidade do solo e da produtividade das espécies cultivadas nessas áreas.

O objetivo desse estudo foi avaliar os efeitos de diferentes formas de manejo da água e da aplicação do fertilizante potássico na cultura de arroz irrigado, quanto a alguns atributos químicos do solo.

\section{MATERIAL E MÉTODOS}

O estudo foi conduzido durante três anos consecutivos (1991/92, 1992/93 e 1993/94) na Fazenda Palmital, da Embrapa Arroz e Feijão, no município de Goianira, GO, em um solo Gley Pouco Húmico, textura argilo-arenosa. O delineamento experimental foi o inteiramente casualizado, conforme metodologia apresentada por Chacín Lugo (1997) em parcelas subdivididas, com oito repetições. As parcelas foram constituídas pela combinação de duas formas de manejo da água na cultura de arroz irrigado: $\mathrm{MA}_{1}$ - inundação contínua durante todo o ciclo, e $\mathrm{MA}_{2}$ - inundação intermitente na fase vegetativa, seguida de inundação contínua nas fases reprodutiva e de maturação, e três do fertilizante potássico: $\mathrm{K}_{1}$ - adubação potássica $\left(70 \mathrm{~kg} \mathrm{ha}^{-1}\right.$ de $\left.\mathrm{K}_{2} \mathrm{O}\right)$ aplicada por ocasião da semeadura; $\mathrm{K}_{2}$ - adubação potássica parcelada (70 kg ha-1 de $\mathrm{K}_{2} \mathrm{O}$ ), sendo $1 / 3$ aplicado no sulco de plantio, ${ }_{1}^{1 / 3}$ a lanço por ocasião da diferenciação do primórdio floral $\mathrm{e}^{1 / 3}$ a lanço antes da floração, e $\mathrm{K}_{3}$ - meia dosagem da adubação $\left(35 \mathrm{~kg} \mathrm{ha}^{-1}\right.$ de $\mathrm{K}_{2} \mathrm{O}$ ) parcelada, a metade na diferenciação floral e o restante antes da floração, no esquema fatorial ( 2 × 3 ). As subparcelas foram compostas pelas profundidades de amostragens: 0 - 20, 20 - 40, 40 - 60 e 60 - $80 \mathrm{~cm}$. A adubação parcelada do fertilizante potássico foi efetuada manualmente sobre a lâmina de água.

Trinta dias antes da primeira semeadura foram incorporadas 3 tha ${ }^{-1}$ de calcário dolomítico com $70 \%$ de PRNT, na camada de $0-15 \mathrm{~cm}$ de profundidade do solo, por meio de uma enxada rotativa. A necessidade de calcário foi calculada utilizando-se o método de saturação por bases do solo (Fageria \& Stone, 1999). As recomendações de adubação foram baseadas na análise de solo e indicadas para a cultura de arroz, segundo a Comissão de Fertilidade de Solos de Goiás (1988) e Fageria (1999). Na semeadura foram aplicados, a lanço, 30 e $120 \mathrm{~kg} \mathrm{ha}^{-1}$ de $\mathrm{Ne} \mathrm{P}_{2} \mathrm{O}_{5}$, respectivamente; em cobertura, efetuaram-se duas aplicações de $35 \mathrm{~kg} \mathrm{ha}^{-1}$ de $\mathrm{N}$, juntamente com o potássio parcelado. As fontes de $\mathrm{N}, \mathrm{P}_{2} \mathrm{O}_{5}$ e $\mathrm{K}_{2} \mathrm{O}$ foram sulfato de amônio, superfosfato simples e cloreto de potássio, respectivamente; apenas no primeiro cultivo foram usados $40 \mathrm{~kg} \mathrm{ha}^{-1}$ de FTE BR 12 (Malavolta, 1986) como fonte de micronutrientes.

As parcelas foram isoladas por diques, para se efetuar o manejo em separado da água de irrigação. Nos estádios iniciais, a irrigação se deu através da colocação de lâmina de aproximadamente $5 \mathrm{~cm}$ de espessura ("banhos"). Os tratamentos de manejo da água foram iniciados 20 dias após a emergência das plântulas. Na inundação contínua, manteve-se uma lâmina 
Tabela 1. Atributos químicos, composição granulométrica e classe textural de amostras de diferentes camadas de um solo Gley

Pouco Húmico, no início do estudo

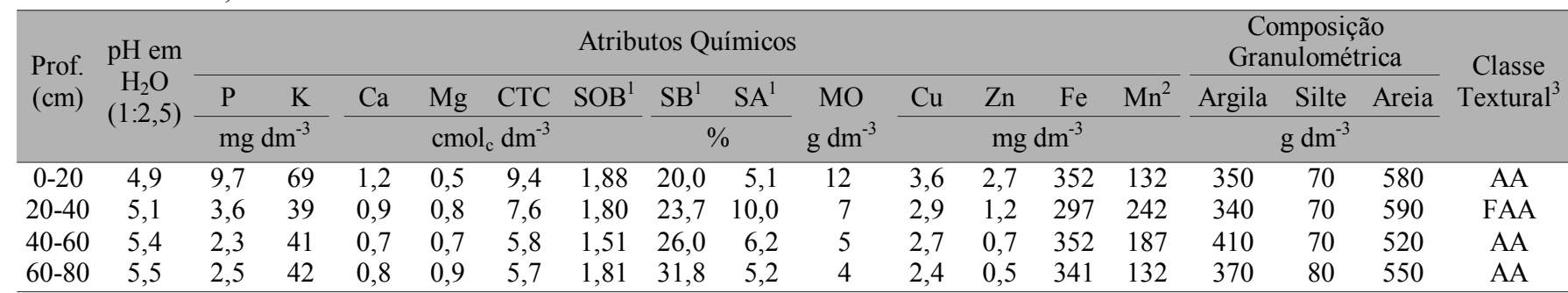

${ }^{1}$ SOB - Soma Base; SB - Saturação Bases; SA - Saturação Al

${ }^{2}$ Foi usado o Mehlich 1 na extração de $\mathrm{P}, \mathrm{K}, \mathrm{Cu}, \mathrm{Zn}, \mathrm{Fe}$ e Mn; o KCI $1 \mathrm{~mol} \mathrm{~L}^{-1}$ na extração de Ca e $\mathrm{Mg}$; $\mathrm{MO}$ - matéria orgânica por oxidação com $\mathrm{K}_{2} \mathrm{Cr}{ }_{2} 0$

${ }^{3}$ AA - Argila arenosa; FAA - Franco argilo-arenosa

de água em torno de $15 \mathrm{~cm}$, até aproximadamente dez dias antes da colheita. Na irrigação intermitente, nova lâmina de água era colocada, após infiltração completa da lâmina de água anterior. As condições do experimento foram descritas previamente por Santos et al. (1999).

Para determinação de alguns atributos químicos, composição granulométrica e classe textural, coletaram-se amostras de solo no início do estudo (Tabela 1), nas camadas de 0 - $20 \mathrm{~cm}, 20$ - 40 $\mathrm{cm}, 40$ - $60 \mathrm{~cm}$ e 60 - $80 \mathrm{~cm}$ de profundidade e após a colheita do terceiro cultivo de arroz irrigado. As análises das amostras de solo foram realizadas de acordo com metodologia apresentada por Silva (1999).

\section{RESULTADOS E DISCUSSÃO}

Não houve interação significativa entre as formas de manejo de água, os manejos de fertilizante potássico e as profundidades de amostragem de solo. As formas de manejo da água influenciaram os valores de $\mathrm{pH}$, saturação por alumínio, a soma de bases e os teores de cálcio, potássio e fósforo nas diferentes profundidades do solo (Tabela 2), e os valores de $\mathrm{pH}$ do solo, em ambos os manejos de água, foram superiores ao determinado no início do estudo (Tabelas 1 e 2), que pode ser atribuído à incorporação do calcário, antes da primeira semeadura do arroz irrigado. A inundação também provoca aumento no $\mathrm{pH}$ da solução do solo (Moraes \& Dynia, 1992); entretanto, esta forma de irrigação foi usada durante todo o ciclo da cultura somente no manejo $\mathrm{MA}_{1}$. Com base na Comissão de Fertilidade de Solos de Goiás (1988) pode-se afirmar que, inicialmente, o solo possuía $\mathrm{pH}$ na classe fortemente ácido $(\mathrm{pH}<5,0)$ na camada superficial e, após três anos de cultivo, passou para a classe medianamente ácido ( $\mathrm{pH}$ entre 5,0 a 5,5). Tanto o $\mathrm{pH}$ determinado no início do estudo quanto aquele após três cultivos, aumentaram com a profundidade. Constatou-se diferença nos valores de $\mathrm{pH}$, em função dos manejos de água apenas na camada superficial (0 $20 \mathrm{~cm}$ ) observando-se maiores valores no manejo $\mathrm{MA}_{2}$. Embora esta diferença na reação do solo tenha sido significativa, sua implicação prática é insignificante, pois 0,1 unidade de $\mathrm{pH}$ não condiciona alteração substancial para o cultivo de arroz irrigado em solo de várzea. Stone et al. (1990) não verificaram diferenças significativas nos valores de $\mathrm{pH}$, ao se comparar diferentes formas de manejo de água, por quatro anos consecutivos.

Resultado inverso foi obtido com a porcentagem de saturação por alumínio na camada superficial do solo. $\mathrm{O}$ tratamento $\mathrm{MA}_{1}$ promoveu aumento relativo de $47 \%$ da saturação por alumínio $(15,8 \%)$ em relação ao $\mathrm{MA}_{2}(10,7 \%)$; também foi constatada diferença significativa de saturação por alumínio na camada de 60 - $80 \mathrm{~cm}$ de profundidade, superior à porcentagem no $\mathrm{MA}_{2}$. Verifica-se, também, que o monocultivo contínuo de arroz irrigado provocou aumento da saturação por alumínio na camada superficial do solo. Este aumento se deve, provavelmente, à aplicação de sulfato de amônio, que tem efeito acidificante no solo. Fageria \& Baligar (2001) relataram que a aplicação de sulfato de amônio como fonte de $\mathrm{N}$ na cultura de arroz irrigado três anos consecutivos, aumentou significativamente o teor de Al na camada superficial do solo.

Os teores de cálcio no perfil abaixo de $20 \mathrm{~cm}$ de profundidade foram significativamente maiores no $\mathrm{MA}_{1}$ que no $\mathrm{MA}_{2}$ havendo, neste tratamento, maior concentração na camada de $20-60 \mathrm{~cm}$ de profundidade, enquanto no $\mathrm{MA}_{1}$ os teores

Tabela 2. Influência do manejo da água de irrigação ${ }^{1,2}$ sobre alguns atributos químicos de um solo Gley Pouco Húmico de várzea

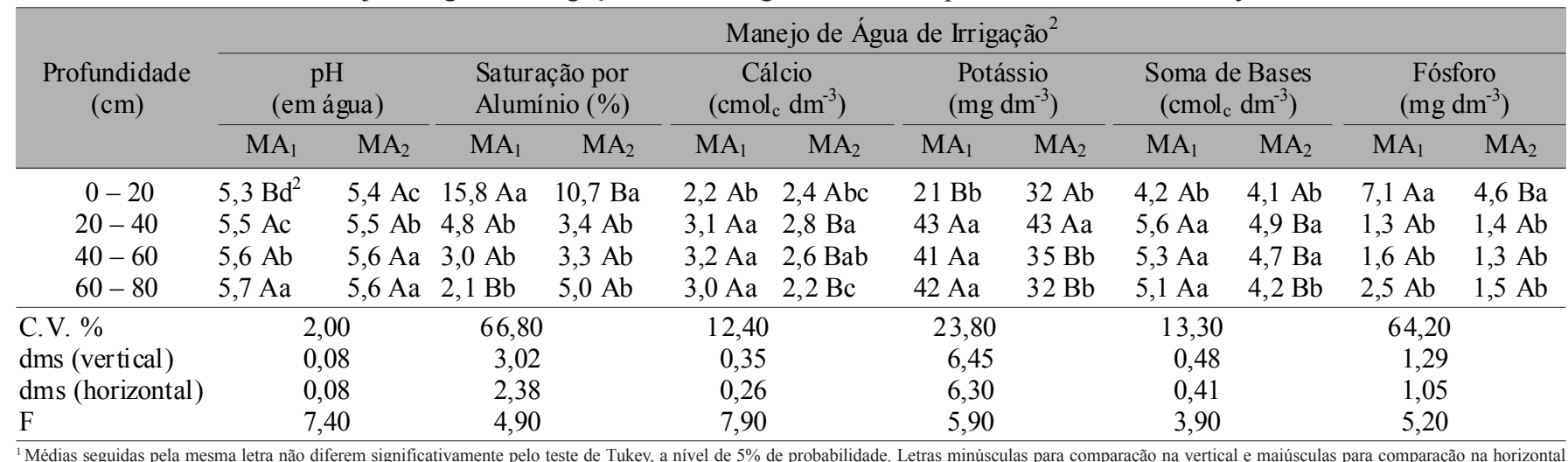

${ }^{1}$ Médias seguidas pela mesma letra não diferem significativamente pelo teste de Tukey, a nível de $5 \%$ de probabilidade. Letras minúsculas para comparação na vertical e maiúsculas para comparação na horizontal ${ }^{2} \mathrm{MA}$ - Inundação contínua durante todo o ciclo e $\mathrm{MA}_{2}$ - Inundação intermitente na fase vegetativa, seguida de inundação contínua nas fases reprodutiva e de maturação 
não diferiram ao longo do perfil, indicando maior lixiviação deste nutriente no $\mathrm{MA}_{1}$, pois na camada mais profunda $(60-80 \mathrm{~cm}) \mathrm{o}$ teor de Ca neste tratamento $\left(3,0 \mathrm{cmol}_{\mathrm{c}} \mathrm{dm}^{-3}\right)$ foi $27 \%$ maior que no $\mathrm{MA}_{2}\left(2,2 \mathrm{cmol}_{\mathrm{c}} \mathrm{dm}^{-3}\right)$. Em ambos os manejos de água, maiores teores de cálcio também podem ser atribuídos à aplicação de calcário, em comparação aos iniciais.

$\mathrm{O}$ teor de $\mathrm{K}$ no $\mathrm{MA}_{1}$ foi significativamente maior nas camadas abaixo da superficial, indicando lixiviação desse nutriente ao longo do perfil do solo amostrado, enquanto no $\mathrm{MA}_{2}$ se observou uma zona de concentração de K na camada de 20 - $40 \mathrm{~cm}$ de profundidade, Tabela 2 . Na camada superficial, o teor de $\mathrm{K}$ foi $52 \%$ superior no $\mathrm{MA}_{2}\left(32 \mathrm{mg} \mathrm{dm}^{-3}\right)$ em relação ao $\mathrm{MA}_{1}\left(21 \mathrm{mg} \mathrm{dm}^{-3}\right)$ e, nas camadas abaixo de $40 \mathrm{~cm}$, maiores valores foram determinados no $\mathrm{MA}_{1}$; portanto, este manejo da água também causou maior lixiviação de $\mathrm{K}$, assim como de cálcio. Resultados semelhantes foram obtidos por Stone et al. (1990) que determinaram maior teor de K na camada de 25 a $40 \mathrm{~cm}$ com a subirrigação e a irrigação intermitente. A lixiviação de íons provenientes da solução do solo ou de fertilizantes nas várzeas, foi relatada por Beltrame et al. (1991) como sendo uma preocupação constante. Empregando o sistema de irrigação por inundação contínua corrente no arroz irrigado, Beltrame et al. (1992) determinaram que a quantidade lixiviada de íon potássio correspondeu a $98,4 \%$ do potássio aplicado. Ponnamperuma (1972) e Moraes \& Freire (1974) relataram que, devido à submersão, o aumento da concentração de $\mathrm{Mn}^{2+} \mathrm{e}$ $\mathrm{Fe}^{2+}$ solúveis causa deslocamento dos cátions trocáveis $\mathrm{Ca}^{2+}$, $\mathrm{Mg}^{2+}$ e $\mathrm{K}^{+}$para a solução do solo e aumenta as perdas dos mesmos por lixiviação, principalmente em solos arenosos. As maiores respostas do arroz irrigado ao $\mathrm{K}$ ocorrem em solos com drenagem pobre que em solos com boa percolação, ou naqueles que são intermitentemente secos e umedecidos. Fageria et al. (1990) observaram movimento do potássio para as camadas inferiores do solo, especialmente nas dosagens mais elevadas do nutriente. Os autores relataram, também, que o potássio do solo é continuamente removido pelas culturas, o que pode acarretar, com o monocultivo contínuo de arroz irrigado, decréscimo na fertilidade das várzeas, devendo servir de alerta com referência à recomendação de potássio para $\mathrm{o}$ arroz irrigado. Para manter o potencial produtivo dos solos de várzea, é necessária a aplicação anual de $\mathrm{K}_{2} \mathrm{O}$, a lanço ou no sulco de plantio.
No perfil, como um todo - Tabela 2, verifica-se que a utilização agrícola desse solo de várzea com o monocultivo contínuo de arroz irrigado, por três anos consecutivos, elevou a soma de bases trocáveis. Esse aumento das bases ao longo do perfil, quando comparado com a análise inicial, se deve à lixiviação de nutrientes aplicados no horizonte superficial e à aplicação do calcário. Em conseqüência da lixiviação dos cátions trocáveis, a soma de bases da camada superficial no $\mathrm{MA}_{1}$ foi significativamente inferior à das camadas mais profundas, enquanto no $\mathrm{MA}_{2}$ os maiores valores foram determinados na camada de 20 - $60 \mathrm{~cm}$ (Tabela 2). A soma de bases no $\mathrm{MA}_{1}$ foi maior que a do $\mathrm{MA}_{2}$, exceto na camada superficial, indicando maior lixiviação dos cátions trocáveis nesse manejo de água e, na camada superficial, o teor de fósforo foi significativamente maior no MA $($ (Tabela 2). Uma das principais causas do aumento da disponibilidade de fósforo, após a inundação, é atribuída à redução do fosfato férrico a fosfato ferroso (Yoshida, 1981). Em ambos os manejos de água, os teores deste nutriente foram menores que o determinado no início do estudo, conforme Tabela 1. O teor de P na camada de $0-20 \mathrm{~cm}$ foi significativamente maior que os das demais camadas, tanto na análise inicial quanto após três cultivos de arroz. Nos horizontes subsuperficiais os teores de P não diferiram. A quantidade de íon fósforo lixiviado proveniente da solução do solo e/ou dos fertilizantes, determinada por Beltrame et al. (1992) representou parcela muito pequena, correspondendo a $1,3 \%$ do fósforo aplicado no solo; com isto, os autores consideraram que as perdas por lixiviação dos íons fósforo, cálcio, magnésio e nitrato, não trazem preocupações maiores no tocante a custos e/ou parcelamento de fertilizantes; contudo, podem causar danos ao ambiente, devido à poluição de cursos de água.

Independentemente do manejo da água, o manejo do fertilizante potássico influenciou o $\mathrm{pH}$, o teor de cálcio no solo e a saturação por alumínio nas diferentes profundidades do solo (Tabela 3). $\mathrm{O} \mathrm{pH}$ aumentou com a profundidade e somente foi afetado pelos manejos do potássio na camada mais profunda $(60-80 \mathrm{~cm})$, porém este efeito não tem implicação prática para o cultivo de arroz irrigado, pois foi detectado abaixo da zona radicular.

O manejo de potássio afetou o teor de Ca no solo apenas na camada superficial, tendo o tratamento $\mathrm{K}_{2}$ propiciado teor do nutriente no solo significativamente maior que os demais. No manejo $\mathrm{K}_{1}$, o teor de Ca na camada superficial foi menor que o

Tabela 3. Influência do manejo do fertilizante potássico ${ }^{1}$ sobre o pH, teor de Ca e saturação por alumínio de um solo Gley Pouco Húmico de várzea

\begin{tabular}{|c|c|c|c|c|c|c|c|c|c|}
\hline \multirow{3}{*}{$\begin{array}{l}\text { Profundidade } \\
\quad(\mathrm{cm})\end{array}$} & \multicolumn{9}{|c|}{ Manejo do Fertilizante Potássico² } \\
\hline & $\mathrm{K}_{1}$ & $\mathrm{~K}_{2}$ & $\mathrm{~K}_{3}$ & $\mathrm{~K}_{1}$ & $\mathrm{~K}_{2}$ & $\mathrm{~K}_{3}$ & $\mathrm{~K}_{1}$ & $\mathrm{~K}_{2}$ & $\mathrm{~K}_{3}$ \\
\hline & \multicolumn{3}{|c|}{ pH (em água) } & \multicolumn{3}{|c|}{ Cálcio $\left(\mathrm{cmol}_{\mathrm{c}} \mathrm{dm}^{-3}\right)$} & \multicolumn{3}{|c|}{ Saturação por Alumínio (\%) } \\
\hline $20-40$ & $5,4 \mathrm{Ac}$ & $5,5 \mathrm{Aa}$ & $5,5 \mathrm{Ab}$ & $2,8 \mathrm{Aa}$ & $3,1 \mathrm{Aa}$ & $2,9 \mathrm{Aa}$ & $5,4 \mathrm{Ab}$ & $3,8 \mathrm{Ab}$ & $3,1 \mathrm{Ab}$ \\
\hline $40-60$ & $5,6 \mathrm{Ab}$ & $5,5 \mathrm{Aa}$ & $5,6 \mathrm{Aa}$ & $2,9 \mathrm{Aa}$ & $3,0 \mathrm{Aa}$ & $2,8 \mathrm{Aa}$ & $3,1 \mathrm{Ab}$ & $3,8 \mathrm{Ab}$ & $2,7 \mathrm{Ab}$ \\
\hline $60-80$ & $5,8 \mathrm{Aa}$ & $5,5 \mathrm{Ab}$ & $5,7 \mathrm{Aa}$ & $2,8 \mathrm{Aa}$ & $2,5 \mathrm{Ab}$ & $2,4 \mathrm{Ab}$ & $1,9 \mathrm{Ab}$ & $4,4 \mathrm{Ab}$ & $4,4 \mathrm{Ab}$ \\
\hline dms (horizontal) & & 0,10 & & & 0,10 & & & 2,94 & \\
\hline $\mathrm{F}$ & & 7,40 & & & 7,90 & & & 4,90 & \\
\hline
\end{tabular}

Médias seguidas pela mesma letra não diferem significativamente pelo teste de Tukey, a nível de $5 \%$ de probabilidade. Letras minúsculas para comparação na vertical e maiúsculas para comparação na horizontal $\mathrm{K}_{1}$ - Adubação potássica $\left(70 \mathrm{~kg} \mathrm{ha}^{-1}\right)$ na semeadura; $\mathrm{K}_{2}$ - Adubação potássica parcelada $\left(70 \mathrm{~kg} \mathrm{ha}^{-1}\right) ; \mathrm{K}_{3}$ - Meia dosagem da adubação (35 kg ha-1) parcelada 
das demais camadas, não se observando uma zona de concentração do nutriente, indicando que a lixiviação deve ter ultrapassado as camadas amostradas; enquanto nos manejos $\mathrm{K}_{2}$ e $\mathrm{K}_{3}$ o teor de cálcio foi maior na profundidade de 20 - 60 cm, observando-se uma zona de concentração do nutriente (Tabela 3 ).

O manejo do fertilizante potássico influenciou a saturação por alumínio somente na camada superficial do solo, obtendo-se menor valor quando se efetuou o parcelamento da maior dosagem de potássio (Tabela 3 ). Em todas as condições do estudo, a saturação por alumínio decresceu sensivelmente com o aumento da profundidade. Estas observações sugerem que no cultivo de arroz irrigado em solo de várzea, a adubação potássica deve ser feita parceladamente.

\section{CONCLUSÕES}

1. O manejo da água e do fertilizante potássico afeta a distribuição dos nutrientes no perfil do solo e, conseqüentemente, a sua disponibilidade para as plantas.

2. A inundação intermitente durante a fase vegetativa com inundação contínua nas fases reprodutiva e de maturação do arroz irrigado e o parcelamento do fertilizante potássico, podem reduzir as perdas de nutrientes em solos de várzea que apresentam percolação excessiva.

3. Alguns atributos químicos do solo podem ser melhorados através do manejo adequado da cultura do arroz irrigado, envolvendo manejo da água e do fertilizante potássico.

\section{LITERATURA CITADA}

Beltrame, L.F.S.; Iochpe, B.; Rosa, S.M. da; Miranda, T.L.G. de. Lixiviação de íons em planossolo vacacaí sob condições de alagamento. Lavoura Arrozeira, Porto Alegre, v.44, n.398, p.9$12,1991$.

Beltrame, L.F.S.; Iochpe, B.; Rosa, S.M. da; Miranda, T.L.G. de. Lixiviação de íons em solo cultivado com arroz irrigado por inundação. Revista Brasileira de Ciência do Solo, Campinas, v.16, n.2, p.203-208,1992.

Chacín Lugo, F.B. Cursos de avances recientes en el diseño y análisis de experimentos. [s.1.]: Universidad Central da Venezuela, 1997. 145p.

Comissão de Fertilidadade de Solos de Goiás (Goiânia, GO). Recomendações de corretivos e fertilizantes para Goiás: $5^{\text {a }}$ aproximação. Goiânia, 1988. 101p. Informativo Técnico, 1

Fageria, N.K. Response of rice to fractional applied potassium in Brazil. Better Crops International, Norcross, v.7, n.2, p.19, 1991.

Fageria, N.K. Adubação e calagem. In: Vieira, N.R. de A.; Santos, A.B. dos; Sant'ana E.P. (eds.). A cultura do arroz no Brasil. Santo Antônio de Goiás: Embrapa Arroz e Feijão, 1999. p.329-353.
Fageria, N.K.; Baligar, V.C. Lowland rice response to nitrogen fertilization. Communication in Soil Science and Plant Analysis, New York, v.32, n.9/10, p.1405-1429, 2001.

Fageria, N.K.; Baligar, V.C.; Writh, R.J.; Carvalho, J.R.P. de. Lowland rice response to potassium fertilization and its effect on $\mathrm{N}$ and P uptake. Fertilizer Research, Dordrecht, v.21, p.157-162, 1990.

Fageria, N.K.; Stone, L.F. Manejo da acidez dos solos de cerrado e de várzea do Brasil. Santo Antônio de Goiás: Embrapa Arroz e Feijão, 1999. 42p. Embrapa Arroz e Feijão. Documentos, 92.

IRRI (Manila, Filipinas). Yield decline: Identifying the causes. Manila, 1994. 2p. IRRI. Report, 2

Islam, A.; Islam, W. Chemistry of submerged soils and growth and yield of rice. I. Benefits from submergence. Plant and Soil, Dordrecht, v.39, n.3, p.555-565, 1973.

Islam, A.; Ullah, S.M. Chemistry of submerged soils and growth and yield of rice. II. Effect of additional application of fertilizers on soil at field capacity. Plant and Soil, Dordrecht, v.39, n.3, p.567-579, 1973.

Malavolta, E. Micronutrientes na adubação. São Paulo: Nagy, 1986. 70p.

Moraes, J.F.V. Efeitos da inundação do solo. II. Influência sobre a absorção de nutrientes e o crescimento de arroz (Oryza sativa L.). Pesquisa Agropecuária Brasileira, Rio de Janeiro, v.8, n.7, p.103-108, 1973.

Moraes, J.F.V.; Dynia, J.F. Alterações nas características químicas e físico-químicas de um solo Gley Pouco Húmico sob inundação e após a drenagem. Pesquisa Agropecuária Brasileira, Brasília, v.27, n.2, p.223-235, 1992.

Moraes, J.F.V.; Freire, C.J.S. Variação do pH, da condutividade elétrica e da disponibilidade dos nutrientes nitrogênio, fósforo, potássio, cálcio e magnésio, em quatro solos submetidos a inundação. Pesquisa Agropecuária Brasileira, Rio de Janeiro, v.9, n.9, p.35-43, 1974.

Ponnamperuma, F.N. The chemistry of submerged soil. Advances in Agronomy, New York, v.24, p.29-96, 1972.

Santos, A.B. dos; Fageria, N.K.; Stone, L.F.; Santos, C. Manejo de água e de fertilizante potássico na cultura de arroz irrigado. Pesquisa Agropecuária Brasileira, Brasília, v.34, n.4, p.565-573, 1999.

Silva, F.C. da (Org.). Manual de análises químicas de solos, plantas e fertilizantes. Brasília: Embrapa Comunicação para Transferência de Tecnologia. 1999. 370p.

Stone, L.F.; Moreira, J.A.A.; Silveira Filho, A. Manejo de água na cultura do arroz: consumo, ocorrência de plantas daninhas, absorção de nutrientes e características produtivas. Pesquisa Agropecuária Brasileira, Brasília, v.25, n.3, p.323-337, 1990.

Yoshida, S. Fundamentals of rice crop science. Los Baños: IRRI, 1981. 269p. 